TP Periodica Polytechnica Mechanical Engineering

62(2), pp. 173-178, 2018

https://doi.org/10.3311/PPme.11851

Creative Commons Attribution (i)

RESEARCH ARTICLE

\section{Damage of the Bone-Cement Interface in Finite Element Analyses of Cemented Orthopaedic Implants}

\author{
Toufik Bousnane ${ }^{1 *}$, Smail Benbarek ${ }^{1}$, Abderahmen Sahli $^{1}$, \\ Boualem Serier $^{1}$, Bel Abbes Bachir Bouiadjra ${ }^{1}$
}

Received 19 December 2017; accepted 20 February 2018

\begin{abstract}
In orthopedic surgery and particularly in total hip arthroplasty, fixation of femoral implant is generally made by the surgical cement. Bone-cement interface has long been implicated in failure of cemented total hip replacement (THA), it is actually a critical site that affect the long-term stability and survival of prosthetic implants after implantation. The main purpose of this study is to investigate the effect of cement penetration into the bone on damage scenario at the interface. Previously most researchers have been performed to study damage accumulation in the cement mantle for different amount of cement penetration. In this work, bone-cement interface integrity has been studied for different mechanical properties. Cohesive traction separation law is used to detect contact damage between cement and bone. Results showed that a larger debonded area was predicted proximally and distally. Adhesion between bone and cement is affected mainly by cement penetration into the bone. Higher cement penetration into the bone leads to a good load transfer. A lower strength of the bone-cement interface due to a lower mechanical property results in faster interface damage. So we advise surgeons to well perpetrate the bone for longterm durability of cemented THA.
\end{abstract}

\section{Keywords}

total hip replacement, finite element analysis, biomaterials, bone-cement interface, damage

\footnotetext{
${ }^{1}$ Department of Mechanical Engineering, University of Sidi Bel Abbes, BP 89, Cite' Ben M'hidi, Sidi Bel Abbes, 22000, Algeria

*Corresponding author, e-mail: Bousnanet@yahoo.fr
}

\section{Introduction}

The use of total hip replacement (THR) prosthesis has become the second most performed surgical procedure every year, it aims to replace the defective natural articulation [1]. The main reason to proceed to this operation is to attenuate the hip pain. Fig. 1 shows a representation of the total hip prosthesis where the stem is fixed to the bone with orthopedic cement. Implants in (THR) can be fixed by either cement or cementless methods in the patient's bones. In both procedures, the stability of the prosthesis in the hosted bone plays an important role in the long-term durability of the operation $[2,3]$.

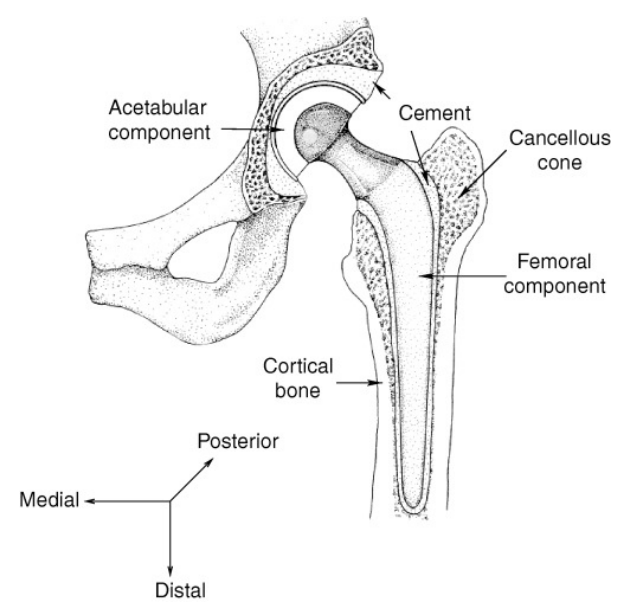

Fig. 1 Total hip prosthesis

Femoral component loosening of cemented hip replacements is still the most frequent cause of revision arthroplasty. In fact, the failure of the prosthesis in the absence of infection is the most recognized cause of the long term loosening of the prosthesis. When subjected to external loads, the cement becomes the weakest part of the prosthesis due to its lower mechanical properties and brittle behavior [4]. So, a deeper understanding of the factors determining the damage process in acrylic bone cement is required and the mechanical integrity of the cement must be maintained for as long as possible to reduce loosening rate. It is widely considered that the long-term stability of cemented hip implants critically depends on three elements (bone, cement, and femoral stem) and their two corresponding interfaces (the 
stem-cement and bone-cement). Autopsy of retrieved hip prostheses have shown that stem-cement debonding and cement cracking are an important events in the failure process of the femoral side. These two events are the first steps of damage [5].

However, in cemented prosthetic replacement, deterioration of the bonded interfaces between bone cement, femur, and stem has known as the most immediate cause for loosening failure of artificial hip joints. Consequently, it is clear to see that establishing the best possible interface between cement and bone should be a primary concern in (THR). Several researchers have shown that the long-term stability of cemented THR depends on the bond between bone and cement [6]. Early cement damage around the femoral stem has also been found to lead to implant loosening [7]. In the other hand fatigue failure of the cement mantle has been also identified as a possible loosening mechanism of the femoral prosthesis. A small cement fractures were found proximally in the cement mantle in the region adjacent to the bone-cement interface $[8,9]$. The role of these fractures that emanate from bone is poorly understood since a lot of research efforts have focused on the fracture process from voids or from the stem-cement interface. Improved cementing techniques have been developed to significantly reduce cement failure. They aim to improve mechanical interlocking between the bone and the cement $[10,11]$. In this sense, most methods have focused on sustained pressurization, reduced viscosity of cement and correct timing of prosthesis insertion [12]. Great effort has been made to investigate the factors influencing the bond strength at the bonecement interface, such as interposition of hydroxyapatite granulates at the interface [10]. In addition, many researchers have shown the effect of vacuum mixing of the cement and preparation of the femoral canal $[13,14]$. Several studies have confirmed that the higher pressure applied to the cement, the greater the penetration of cement into the bone, which mean improving the strength of the bone-cement interface [15].

Therefore, the main goal of this study is to analyze using finite element method the influence of mechanical interlocking, between bone and cement, on damage at the interface. A comparison of stress distribution at the interface for different amounts of cement penetration was also analyzed. We have shown the effect of different amounts of interdigitated bone within the cement on damage and stress distribution. The obtained results from this study can help surgeons to predict whether or not an early THR loosening may occur.

\section{Materials and methods \\ 2.1 Numerical Model}

The model is composed of four regions, which are respectively: implant, cement, spongious bone and cortical bone as represented in Fig. 2 with the assembled model [16]. The cemented hip implant was modeled using FE code ABAQUS 6.13. A $3 \mathrm{D}$ tetrahedral element was used to mesh all components and include 801015 elements. The material properties of the total hip prosthesis components are given in Table $1[17,18]$.

Table 1 Material properties used in the finite element model

\begin{tabular}{lcc}
\hline Materials & $\begin{array}{c}\text { Young Modulus } \\
\text { E (MPa) }\end{array}$ & Poisson ratio $v$ \\
\hline Cortical bone & 17000 & 0.30 \\
Spongious bone & 2000 & 0.30 \\
Bone Cement & 2300 & 0.33 \\
Metallic implant & 210000 & 0.30 \\
\hline
\end{tabular}

\subsection{Loading model}

Forces acting on the stems head are varied in magnitude with time during the gait period and can be referred to a dynamic loading as reported by Bounoua et al. [19]. Using an instrumented prosthesis Bergman [20] found that the maximum force acting on the stem's head is about $300 \%$ of the human body weight. Saikko measured the load history by hip joint simulator and announced that the maximum force is $3.5 \mathrm{kN}$ [19]. Therefore, the load of $3.5 \mathrm{KN}$ value is used in this work. The femur was fully encastred at its distal end in the knee joint $[21,22]$ as shown in Fig. 3. Contact between cement and stem is considered as fully bounded. Surface to surface contact with small sliding and cohesive behavior was considered for the bone-cement interface property.

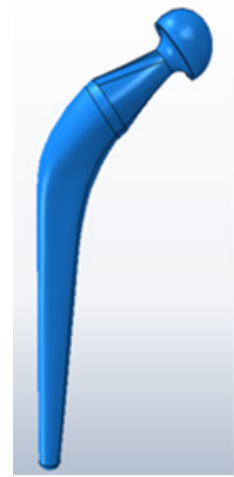

(1)

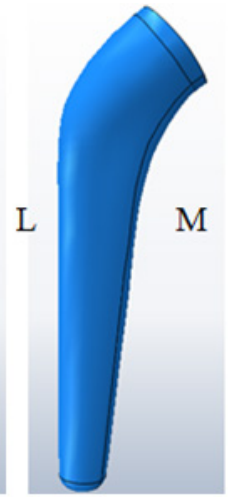

(2)

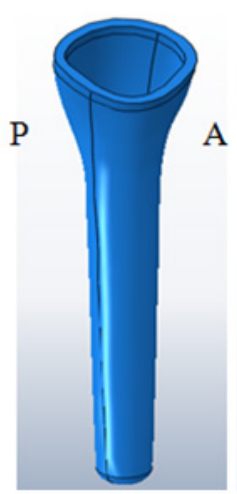

(3)

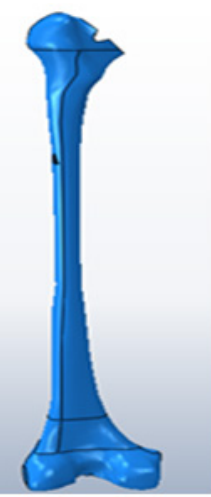

(4)

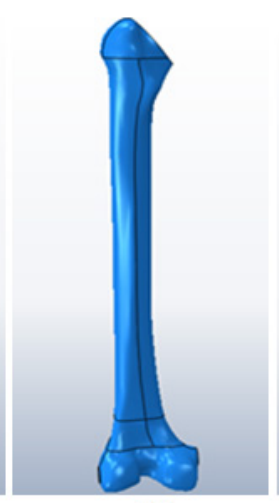

(5)

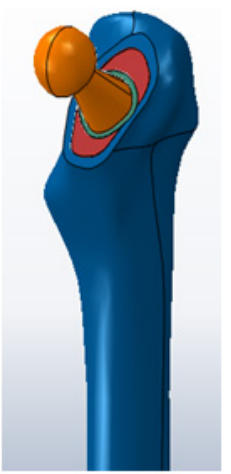

(6)

Fig. 2 Three dimensional model: 1 implant, 2, 3 cement ((A) anterior, (P) posterior, (L) lateral, (M) medial), 4 spongious bone, 5 cortical bone and 6 assembled model 


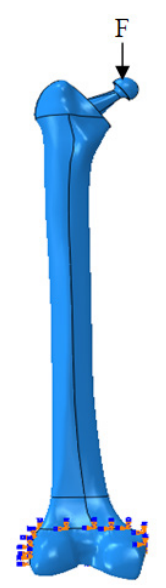

Fig. 3 Loading and boundary conditions

\subsection{Interface damage modeling}

Abaqus assumes initially linear elastic behavior followed by initiation and evolution of damage for traction-separation model. An elastic constitutive matrix Eq. (1) that relates the normal and shear stresses to the normal and shear separations across the interface is written in terms of the elastic behavior components.

$$
t=\left\{\begin{array}{l}
t_{n} \\
t_{s} \\
t_{t}
\end{array}\right\}=\left[\begin{array}{lll}
k_{n n} & k_{n s} & k_{n t} \\
k_{n s} & k_{s s} & k_{s t} \\
k_{n t} & k_{s t} & k_{t t}
\end{array}\right] \quad\left\{\begin{array}{l}
\delta_{n} \\
\delta_{s} \\
\delta_{t}
\end{array}\right\}=K \delta .
$$

Damage modeling allows simulation of degradation and eventual failure of two surfaces initially fully bonded. Failure consists of two parts: a damage initiation criterion and a damage evolution law. Damage herein is considered only under normal and shear tractions, never under compression. Fig. 4 represent a traction-separation response with a failure mechanism.

Damage initiation refers to the beginning of degradation at a contact point. Degradation begins when contact stresses related to contact separations satisfy damage initiation criteria. Several damage initiation's criteria are available in abaqus library. In this study we used the Maximum separation criterion, which assumed that damage initiates when the maximum separation ratio reaches a value of one as defined in Eq. (2)

$$
\max \left\{\frac{\left\langle\delta_{n}\right\rangle}{\delta_{n}^{0}}, \frac{\delta_{s}}{\delta_{s}^{0}}, \frac{\delta_{t}}{\delta_{t}^{0}}\right\}=1 .
$$

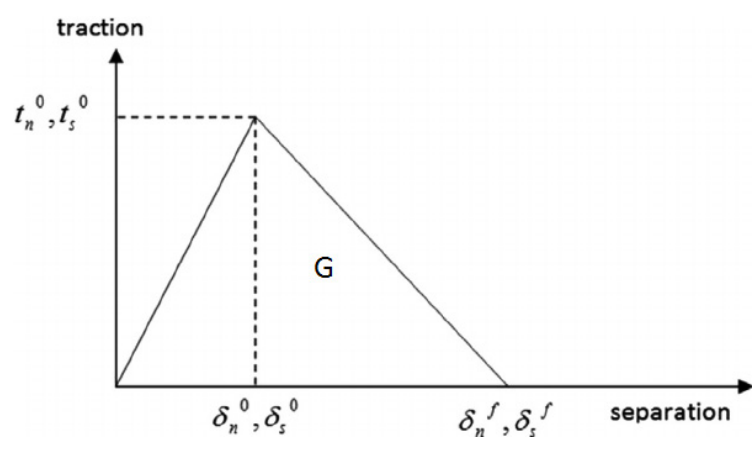

Fig. 4 Traction-separation response

The symbol \langle\rangle used to signify that a purely compressive displacement does not initiate damage. $\delta_{n}^{0}, \delta_{s}^{0}$ and $\delta_{t}^{0}$ represent the peak values of the contact separation.

Damage evolution law expresses the rate at which the stiffness is degraded once initiation criterion is reached, and is defined by the energy that is dissipated as a result of the damage process, i.e. the fracture energy. This energy is equal to the area under the traction-separation curve (Fig. 4). Evolution of the damage variable, $\mathrm{D}$, that abaqus uses is:

$$
D=\frac{\delta_{m}^{f}\left(\delta_{m}-\delta_{m}^{0}\right)}{\delta_{m}\left(\delta_{m}^{f}-\delta_{m}^{0}\right)}, \quad \begin{cases}D=0, & \delta_{m}=\delta_{m}^{0} \\ D=1, & \delta_{m}=\delta_{m}^{f}\end{cases}
$$

where $\delta_{m}^{0}, \delta_{m}^{f}$ and $\delta_{m}$ refers respectively to the values of separation at damage initiation, complete failure and the calculated separation during the analysis [23]. In this study, cement penetration means the microinterlock between cement and bone as shown in Fig. 5. Improving cement penetration leads to high interface mechanical properties. Three amounts of cement penetration $\left(\mathrm{Q}_{\mathrm{CP}}\right)$ were considered from the experimental study of Mann et al. [12]. The computed mechanical properties in shear and normal directions are shown in Table 2.

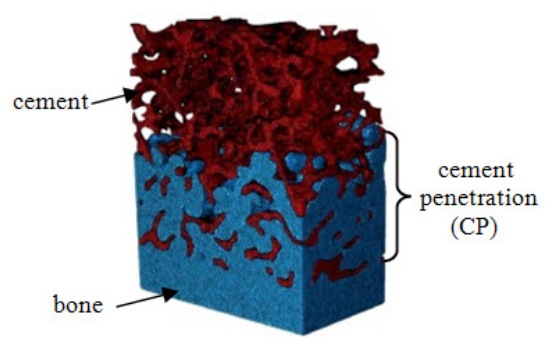

Fig. 5 Cement penetration into bone

\begin{tabular}{|c|c|c|c|c|c|}
\hline $\mathrm{Q}_{\mathrm{CP}}(\mathrm{mg} / \mathrm{cc} \mathrm{mm})$ & & $\mathrm{t}(\mathrm{MPa})$ & $\delta(\mathrm{mm})$ & $\mathrm{K}(\mathrm{MPa} / \mathrm{mm})$ & $\mathrm{G}(\mathrm{N} / \mathrm{mm})$ \\
\hline \multirow{2}{*}{100} & Shear & 1.3046 & 0.082 & 15.91 & 0.4459 \\
\hline & Normal & 1.0634 & 0.070 & 15.19 & 0.2218 \\
\hline \multirow{2}{*}{263.4} & Shear & 2.1111 & 0.082 & 25.75 & 1.0698 \\
\hline & Normal & 1.4758 & 0.070 & 21.08 & 0.4796 \\
\hline \multirow{2}{*}{478.5} & Shear & 3.1728 & 0.082 & 38.69 & 1.8913 \\
\hline & Normal & 2.0187 & 0.070 & 28.83 & 0.8190 \\
\hline
\end{tabular}

Table 2 Different amounts of cement penetration $\left(\mathrm{Q}_{\mathrm{CP}}\right)$ with apparent strength $(\mathrm{t})$, maximum relative displacement in the linear region $(\delta)$, stiffness $(\mathrm{K})$ and fracture energy $(\mathrm{G})$; in shear and normal directions for the bone-cement interface. Mann et al. [22] 


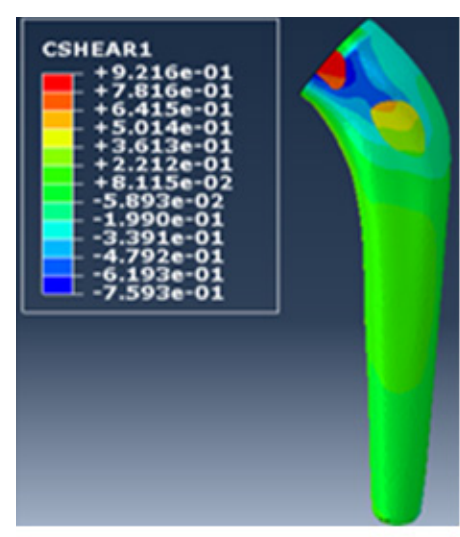

a

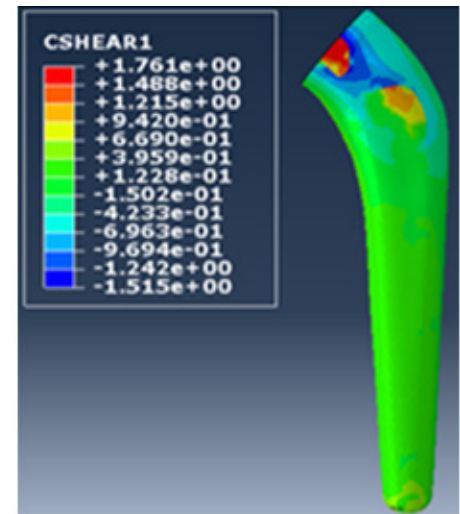

b

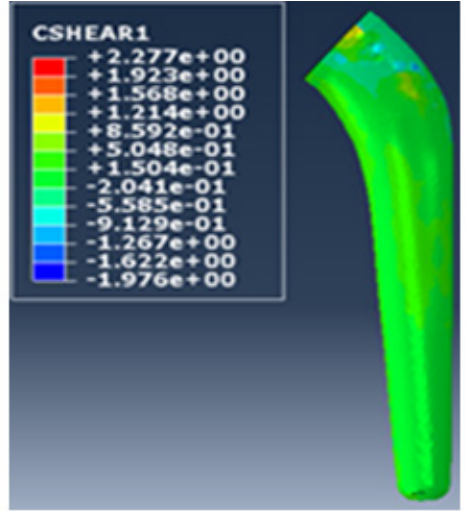

$\mathrm{c}$

Fig. 6 Horizontal shear contact stress distribution for different amounts of cement penetration: (a) $Q_{C P}=100$, (b) 263.4 and (c) $478.5 \mathrm{mg} / \mathrm{cc} \mathrm{mm}$

Contact status (CSTATUS) is the variable that we can evaluate damage with it. The color of interface is red if there are no contact separations, green when there are separations but $0<\delta<\delta^{0}$ and blue if $\delta$ reaches $\delta^{f}$.

\section{Results and Discussions}

Analysis of contact between cement and bone after load application has a great importance for knowing stability of cemented hip implants. The bone-cement interface plays a significant role, which may lead to implant loosening.

In the following sections we analyzed shear stresses and contact pressure at the bone-cement interface. Then, the effect of mechanical interlocking on contact opening and contact status (damaged or not) are also analyzed. This analysis allows us predicting the quality of mechanical cohesion of the interface and recognize the effect of cement penetration on damage process.

\subsection{Horizontal shear contact stress distribution}

Fig. 6 illustrates contact shear stress distribution and its magnitude for different studied cases with respect to amounts of cement penetration (interdigitation) into the bone. In Fig. 6.a, shear stress concentration found in regions where cement came into direct contact with the cortical bone. The remain regions were less exposed with uniform distribution which increased gradually from the proximal to distal region. Also, for different studied cases, the high stress area became small when cement penetration increased and its magnitude can reach $2.3 \mathrm{MPa}$. So, as cement penetration increases, stiffness also increases and causes stress concentration in some regions at the interface. One notices that the higher the penetration is, the greater the stress become uniform at the interface. In addition, the THR loads transfer via shear across the material's interfaces mainly at the proximal and a little bit at the distal regions.

\subsection{Vertical shear contact stress distribution}

Distribution and magnitude of shear stress at the bone-cement interface is shown in Fig. 7. The same distribution as the first one is found for the vertical shear. Regions with high

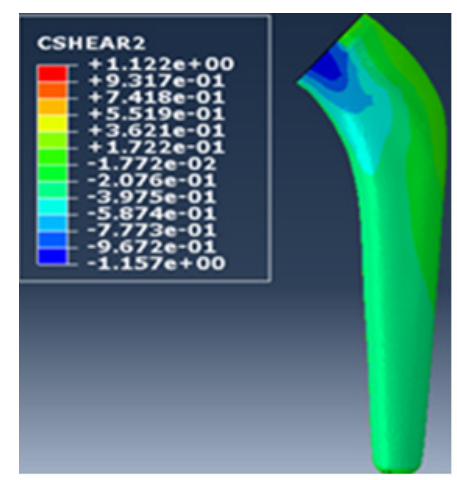

a

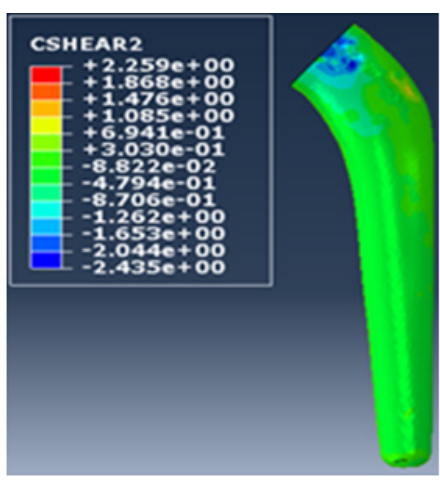

b
Fig. 7 Vertical shear contact stress distribution for different amounts of cement penetration: (a) $\mathrm{Q}_{\mathrm{CP}}=100$ and (c) $478.5 \mathrm{mg} / \mathrm{cc} \mathrm{mm}$

stress were always localized proximally, the maximum stress (2.3 MPa) corresponds to a good cement penetration. Karrholm et al. [24] have found that shear damage to the bone-cement interface could be an important contributor to loosening of cemented femoral components. So, shear stress present a dangerous risk for failure at the interface. Shear strength at the bone-cement interface has been reported in the range of 2-12 MPa. So the highest stress found in this study (2.3 MPa) can represent a risk of fracture and fatigue can affect the long-term stability of the system.

\subsection{Contact pressure distribution}

Fig. 8 shows contact pressure distribution for different amounts of cement penetration. For the first case $Q_{C P}=100 \mathrm{mg} /$ $\mathrm{cc} \mathrm{mm}$, the majority of the interface is in tension (gray region in Fig. 8.a') except some regions that appear proximally and distally at the lateral and medial side respectively with low compression (less than 1.5 $\mathrm{MPa}$ ). In the last two cases $\mathrm{Q}_{\mathrm{CP}}=263.4$ and $463.5 \mathrm{mg} / \mathrm{cc} . \mathrm{mm}$, Fig. 8.b' and Fig. 8.c', it is clear that areas in compression increase, and tension is in specific location with very important level. As a result, if cement penetration increases then adhesion becomes great. In the other hand, when cement penetration is high, it causes a stress concentration. 


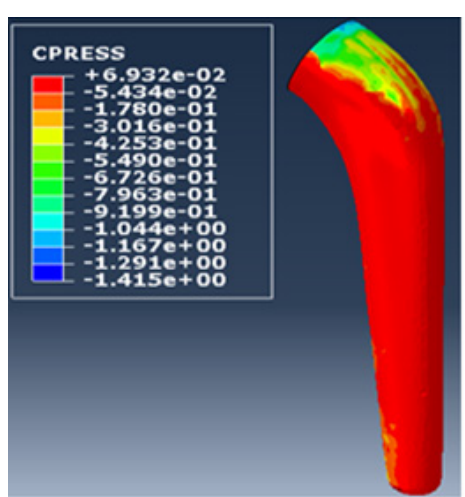

a

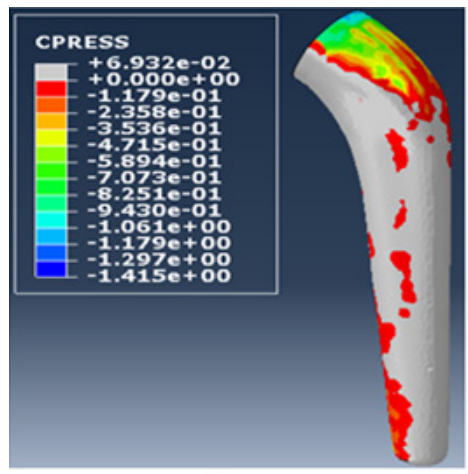

$a^{\prime}$

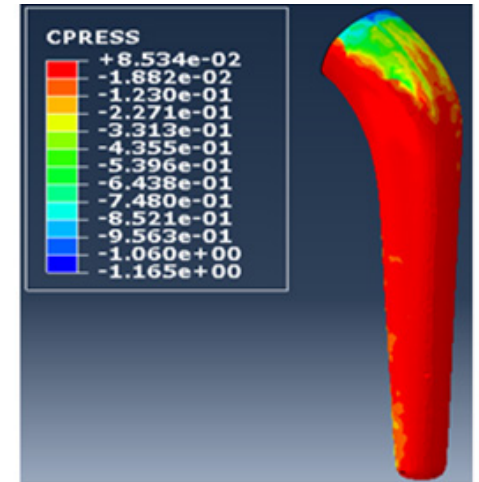

b

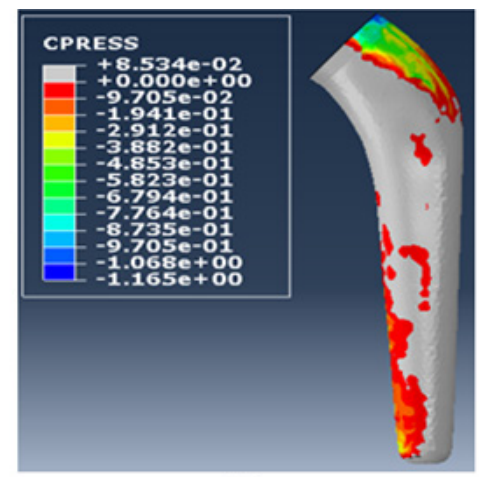

$\mathbf{b}^{\prime}$

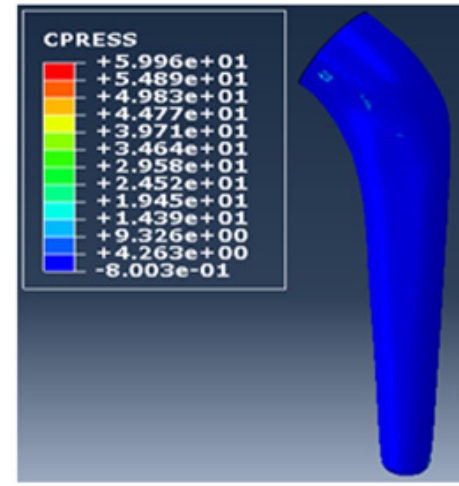

c

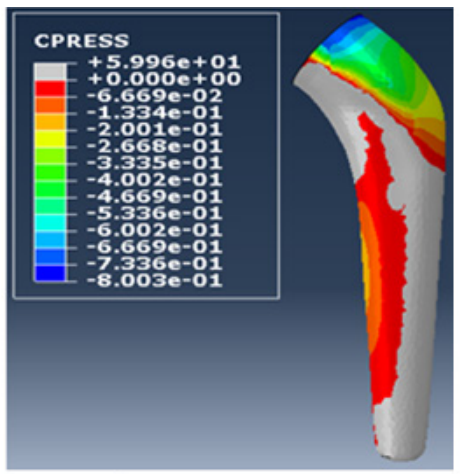

$\mathbf{c}^{\prime}$

Fig. 8 Contact pressure distribution for different amounts of cement penetration: (a) $\mathrm{Q}_{\mathrm{CP}}=100$, (b) $263.4 \mathrm{and}$ (c) $478.5 \mathrm{mg} / \mathrm{cc} \mathrm{mm}$;

in figure $\left(a^{\prime}, b^{\prime}, c^{\prime}\right)$ gray regions are in traction

\subsection{Interface opening distribution}

Fig. 9 shows contact opening distribution and its magnitude at the interface for different amounts of cement penetration. In Fig. 9.a we notice two extend regions with high contact opening, one proximally and the other distally at the lateral and medial side, respectively. As cement penetration increases, we notice localized regions with high contact opening and can reach $0.05 \mathrm{MPa}$ as on the top at the proximal zone.

\subsection{Interface status distribution}

Damage of the bone-cement interface for different amounts of cement penetration into the bone has been represented in Fig. 10. Interface mechanical properties depend on the amount of cement penetration into the bone as Pérez [25] noticed. In the beginning of the simulation, the bone-cement interface was perfectly intact and bonded. For the first case (QCP $=100 \mathrm{mg} /$ cc $\mathrm{mm}$ ), damage occurred proximally and at the lateral side. Important damaged region also appeared distally and at the medial side (Fig. 10.a). One can notice that when cement is not well penetrated into the bone, highest concentration of damage appeared at the interface. Consequently, this leads to the loosening of the implant. Contrary results are observed with highest mechanical properties (strengths) at the interface. This results are supported by the finding of the Pérez et al. [15] about bonecement interface strength in which almost no debonding was predicted for high strength. Damage is clearly non uniform and it has the lowest rate for highest amount of cement penetration.

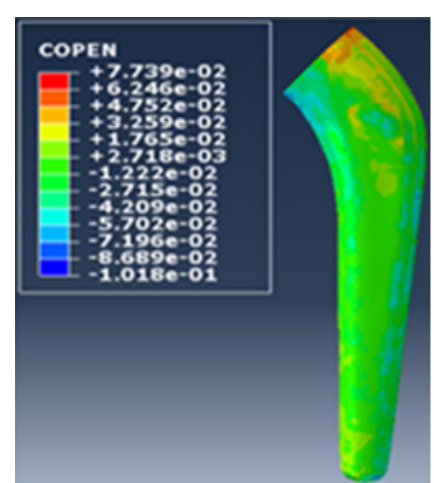

a

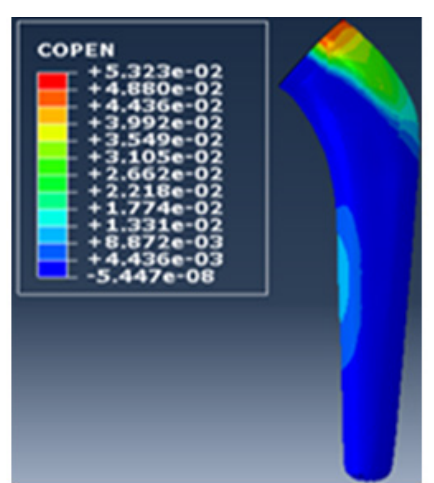

b
Fig. 9 Contact opening distribution for different amounts of cement penetration: (a) $\mathrm{Q}_{\mathrm{CP}}=100$, and (b) $478.5 \mathrm{mg} / \mathrm{cc} \mathrm{mm}$

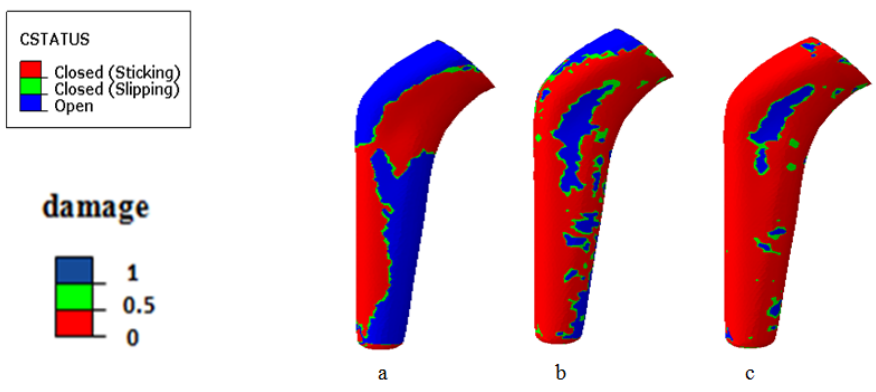

Fig. 10 Contact status distribution for different amounts of cement penetration: (a) $\mathrm{Q}_{\mathrm{CP}}=100$, (b) 263.4 and (c) $478.5 \mathrm{mg} / \mathrm{cc} \mathrm{mm}$ 


\section{Conclusion}

The presented study aimed to investigate damage behavior at the bone-cement interface through finite element simulation. The key issues in this study are related to the modeling of the interfacial characteristics associated with surface damage criteria. The following conclusions could be deduced from this work:

- The orthopedic cement is highly stressed at regions where it comes in direct contact with the cortical bone.

- Interface shear stresses are high and can represent a risk of damage.

- Proximal and distal regions are the most exposed to damage.

- A high strength of the bone-cement interface due to a high amount of interdigitated bone resulted in low rate of damage.

- Preparation of the bone surface enhance the bone-cement interface's mechanical properties.

\section{References}

[1] Pastrav, L., Devos, J., Van der Perre, G., Jaecques, S. "A finite element analysis of the vibrational behaviour of the intra-operatively manufactured prosthesis-femur system." Medical Engineering \& Physics. 31, pp. 489-494. 2009.

https://doi.org/10.1016/j.medengphy.2008.11.017

[2] Speirs, A., Slomczykowski, M., Orr, T., Siebenrock, K., Nolte, L.-P. "Three-dimensional measurement of cemented femoral stem stability: an in vitro cadaver study." Clinical Biomechanics. 15, pp. 248-255, 2000. https://doi.org/10.1016/S0268-0033(99)00079-0

[3] Bialoblocka-Juszczyk, E., Baleani, M., Cristofolini, L., Viceconti, V. "Fracture properties of an acrylic bone cement." Acta of Bioengineering and Biomechanics. 10, p. 21. 2008.

[4] Belgherras, M. E., Serier, B., Benouis, A., Hachemi, L. "Mechanical Behavior of Bone Cement under Dynamic Loading." Periodica Polytechnica Mechanical Engineering. 61, pp. 204-212. 2017. https://doi.org/10.3311/PPme.9672

[5] Pérez, M., Garcia-Aznar, J., Doblare, M., Seral, B., Seral, F. "A comparative FEA of the debonding process in different concepts of cemented hip implants." Medical Engineering \& Physics. 28, pp. 525-533. 2006. https://doi.org/10.1016/j.medengphy.2005.09.007

[6] Tong, J., Wong, K., Lupton, C. "Determination of interfacial fracture toughness of bone-cement interface using sandwich Brazilian disks." Engineering Fracture Mechanics. 74, pp. 1904-1916. 2007. https://doi.org/10.1016/j.engfracmech.2006.02.014

[7] Race, A., Miller, M., Ayers, D., Mann, K. "Shrinkage of vacuum mixed cement causes interface gaps: gap distribution depends on stem surface finish." Orthopaedic Proceedings. 86(SUP), p. 9. 2004.

[8] Race, A., Miller, M. A., Ayers, D. C., Mann, K. A. "Early cement damage around a femoral stem is concentrated at the cement/bone interface." Journal of Biomechanics. 36, pp. 489-496. 2003. https://doi.org/10.1016/S0021-9290(02)00460-8

[9] Cristofolini, L., Savigni, P., Teutonico, A. S., Viceconti, M. "In vitro load history to evaluate the effects of daily activities on cemented hip implants." Acta of Bioengineering and Biomechanics. 5, pp. 77-88. 2003.

[10] Ni, G., Choy, Y., Lu, W., Ngan, A., Chiu, K., Li, Z., Tang, B., Luk, K. "Nano-mechanics of bone and bioactive bone cement interfaces in a load-bearing model." Biomaterials. 27, pp. 1963-1970. 2006. https://doi.org/10.1016/j.biomaterials.2005.09.044
[11] Wang, Y., Han, P., Gu, W., Shi, Z., Li, D., Wang, C. "Cement oscillation increases interlock strength at the cement-bone interface." Orthopedics. $32,2009$.

https://doi.org/10.3928/01477447-20090501-19

[12] Ravenscroft, M., Charalambous, C., Mills, S., Woodruff, M., Stanley, J. "Bone-cement interface strength in distal radii using two medullary canal preparation techniques: carbon dioxide jet cleaning versus syringed saline." Hand Surgery. 15, pp. 95-98. 2010.

https://doi.org/10.1142/S0218810410004618

[13] Liptakova, T., Lelovics, H., Necas, L. "Variations of temperature of acrylic bone cements prepared by hand and vacuum mixing during their polymerization." Acta of Bioengineering and Biomechanics. 11, pp. 47-51. 2009.

[14] Horne, J., Bruce, W., Devane, P., Teoh, H. "The effect of different cement insertion techniques on the bone-cement interface." The Journal of Arthroplasty. 17, pp. 579-583. 2002.

https://doi.org/10.1054/arth.2002.32695

[15] Perez, M., Garcia-Aznar, J., Doblare, M. "Does increased bone-cement interface strength have negative consequences for bulk cement integrity? A finite element study." Annals of Biomedical Engineering. 37, pp. 454466. 2009.

https://doi.org/10.1007/s10439-008-9616-7

[16] Pacific Research Labs. "Biomed Town." [Online]. Available from: https:// www.biomedtown.org/. [Accessed: 9th October 2012]

[17] Wirtz, D. C., Schiffers, N., Pandorf, T., Radermacher, K., Weichert, D., Forst, R. "Critical evaluation of known bone material properties to realize anisotropic FE-simulation of the proximal femur." Journal of Biomechanics. 33, pp. 1325-1330. 2000.

https://doi.org/10.1016/S0021-9290(00)00069-5

[18] Dalstra, M., Huiskes, R. "Load transfer across the pelvic bone." Journal of Biomechanics. 28, pp. 715-724. 1995. https://doi.org/10.1016/0021-9290(94)00125-N

[19] Bounoua, N., Belarbi, A., Belhourari, M., Bachir Bouiadjra, B. "Stress intensity for micro-crack emanating from micro-cavity in cement of reconstructed acetabulum." Mechanika. 20, pp. 527-534. 2014. http://doi.org/10.5755/j01.mech.20.6.9157

[20] Bergmann, G., Deuretzbacher, G., Heller, M., Graichen, F., Rohlmann, A., Strauss, J., Duda, G. "Hip contact forces and gait patterns from routine activities." Journal of Biomechanics. 34, pp. 859-871. 2001. https://doi.org/10.1016/S0021-9290(01)00040-9

[21] Sakai, R., Sato, K., Itoman, M., Mabuchi, K. "Finite element analysis of the effect of proximal interlocking on primary fixation of the Intra-Medullary Cruciate Stem." Journal of Orthopaedic Science. 14, pp. 85-95. 2009. https://doi.org/10.1007/s00776-008-1293-8

[22] El-Sheikh, H., MacDonald, B., Hashmi, M. "Material selection in the design of the femoral component of cemented total hip replacement." Journal of Materials Processing Technology. 122, pp. 309-317. 2002. https://doi.org/10.1016/S0924-0136(01)01128-1

[23] Abaqus 6.13 Documentation. Abaqus Analysis User's Guide, Surfacebased cohesive behavior, Section 31.1.10.

[24] Karrholm, J., Borssen, B., Lowenhielm, G., Snorrason, F. "Does early micromotion of femoral stem prostheses matter? 4-7-year stereoradiographic follow-up of 84 cemented prostheses." Bone \& Joint Journal. 76, pp. 912-917. 1994.

[25] Perez, M., Palacios, J. "Comparative finite element analysis of the debonding process in different concepts of cemented hip implants." Annals of biomedical engineering, 38, pp. 2093-2106. 2010. https://doi.org/10.1007/s10439-010-9996-3 